\title{
Effect of Unequal Lot Sizes, Variable Setup Cost, and Carbon Emission Cost in a Supply Chain Model
}

\author{
Biswajit Sarkar, ${ }^{1}$ Sharmila Saren, ${ }^{2}$ Debjani Sinha, ${ }^{2}$ and Sun Hur ${ }^{1}$ \\ ${ }^{1}$ Department of Industrial \& Management Engineering, Hanyang University, Ansan, Gyeonggi-do 426 791, Republic of Korea \\ ${ }^{2}$ Department of Applied Mathematics with Oceanology and Computer Programming, Vidyasagar University, Midnapore 721 102, India \\ Correspondence should be addressed to Sun Hur; hursun@hanyang.ac.kr
}

Received 21 August 2015; Accepted 5 October 2015

Academic Editor: Paulina Golinska

Copyright (c) 2015 Biswajit Sarkar et al. This is an open access article distributed under the Creative Commons Attribution License, which permits unrestricted use, distribution, and reproduction in any medium, provided the original work is properly cited.

\begin{abstract}
Due to heavy transportation for single-setup multidelivery (SSMD) policy in supply chain management, this model assumes carbon emission cost to obtain a realistic behavior for world environment. The transportation for buyer and vendor is considered along with setup cost reduction by using an investment function. It is assumed that the shipment lot size of each delivery is unequal and variable. The buyer inspects all received products and returns defective items to vendor for reworking process. Because of this policy, end customers will only obtain nondefective items. The analytical optimization is considered to obtain the optimum solution of the model. The main goal of this paper is to reduce the total cost by considering carbon emission during the transportation. A numerical example, graphical representation, and sensitivity analysis are given to illustrate the model.
\end{abstract}

\section{Introduction}

Carbon emission cost affects the capital investment of any manufacture/production industry. There are several research papers in the literature where carbon emission cost is taken as fixed. But this assumption is unrealistic as transporting of lot size may be variable as per demand of buyers. Hence, carbon emission cost may also be treated as variable. Nag and Parikh [1] considered several important matters as time series estimates of indirect carbon emissions per unit of power consumption and baseline emissions for the power sector till 2015. Butler et al. [2] obtained differences between the contributions of various sectors to the total emissions from each city and connect these differences to different methodologies. Ma et al. [3] examined if the global climate change effects were taken into consideration during rapid economic development of China. They described a study of energy consumption and carbon emissions in Tianj during the period from 1995 to 2007. Their research model determined the primary causes of carbon emissions and put forward suggestions for carbon emission reduction in energy consumption. Wygonik and Goodchild [4] designed an emission minimization vehicle routing problem (VRP) with time windows. In their model, they provided a stable relationship between monetary cost and kilograms of $\mathrm{CO}_{2}$. Their results suggest the most effective way to reduce cost and emissions. Hua et al. [5] observed the way of carbon footprints in inventory management under the carbon emission trading mechanism. Bachmann and Van Der Kamp [6] addressed an approach to quantify monetised environmental benefits related to reduction in air pollutant emissions. Zhang et al. [7] studied an evolutionary game model to obtain the promotional effect of the rising oil price on companies behaviour of carbon emission reduction. Their research observed the theoretical reference for promulgating rational low carbon policies.

Setup cost is the cost for setting a production system and configure all production batch-related works. It is important for many manufacturing industries to reduce the setup cost as this cost is directly related to the total cost. Most of the existing literatures stated that setup cost is a fixed cost. This setup cost can be reduced by a small capital investment. Hong et al. [8] investigated three production policies under nonconstant, deterministic demand, and dynamic setup cost reduction. They developed a lot sizing and an investment 
solution procedure to decrease the dynamic setup cost. Ouyang et al. [9] considered that lead time demand follows a normal distribution and optimized lot size, reorder point, process quality, setup cost, and lead time. They used minmax distribution-free approach to solve the problem. They explained the way of setup cost reduction by investing some initial investment. Chuang et al. [10] derived periodic review inventory models with a mixture of backorders and lost sales by controlling lead time and setup cost simultaneously to minimize inventory operating cost. On the other hand, it is considered that probability distribution of the protection interval, that is, review period plus lead time, demand is unknown, but its first two moments are given. Hou [11] investigated an economic production quantity (EPQ) model with imperfect production processes to reduce setup cost. Later, Sarkar and Majumder [12] developed vendor-buyer supply chain model with vendors setup cost reduction strategy. Diaby et al. [13] discussed the issue of investing in reduced setup times and defect rate reductions along with the corresponding optimal levels of investments and optimal production cycle time for each product. They assumed several cases of product-specific quality improvements and joint-product quality improvements. Sarkar and Moon [14] provided an imperfect production process in which they discussed the relationship between quality improvement, reorder point, and lead time with backorder rate. They assumed that lead time demand follows a normal distribution and applied the distribution free approach for the lead time demand to minimize total system cost. In their model, they optimized setup cost, lot size, lead time, reorder point, and process quality parameter. Sarkar et al. [15] presented a continuous-review inventory model with quality improvement, service level constraint, and setup cost reduction. They considered some distribution-free approach and minimized the total system cost against the worst possible distribution scenario.

It is assumed that whenever the buyer places an order to the vendor, the vendor shipped those products in equal delivery lot sizes. The produced lot may be shifted in partial batches to balance holding cost and setup cost. Goyal and Szendrovits [16] considered a constant lot size model to obtain economic lot size and batch sizes for each stage. They assumed in their research model that equal or unequal sized batches can be shipped from one stage to the next and the total number of batches may differ across stages. Transportation of partial lots is provided between stages in their proposed model. Hoque and Kingsman [17] obtained a new heuristic solution procedure for the constant lot size model for the production of a single product requiring processing through a fixed sequence of manufacturing stage. Bogaschewsky et al. [18] extended previous research works in this field by considering multistage production model in which unequal sized batches are produced. An optimization method is constructed to measure the economic lot size and optimal batch sizes for each stage by assuming setup costs, inventory holding costs, and transportation costs in their model. Siajadi et al. [19] proposed a shipment policy to minimize the joint total relevant cost (JTRC) for both vendor and buyer. Considering two-buyer and more than two-buyer cases, they obtained exact and approximate optimum solutions. Though several models considered SSMD policy, many models assumed only equal shipments. Zhou and Wang [20] generated a production-inventory model with deteriorating item for a single-vendor single-buyer integrated system. Their model considered the structure of shipment policy. In addition, their model extended to the situation with shortages permitted, based on shortages being allowed to occur only for the buyer. Hoque [21] developed a manufacturer-buyer integrated inventory model by assuming equal/unequal-sized batches delivery. Hariga et al. [22] developed a mixed integer nonlinear program that minimizes total supply chain costs and allows unequal shipment frequencies to the retailers.

Many earlier research works considered an unrealistic assumption that all the produced items are absolutely nondefective. That means after the production process, all the manufactured good is nondefective. But this assumption is not applicable always in reality. During long-run production, imperfect products may occur. With the help of inspection procedure, buyer can obtain nondefective and defective products. After inspection, buyer keeps the nondefective quality items and returned the defective items to vendor for reworking process. By using inspection policy, manufacturing industries are able to provide good quality items into market. Wang and Sheu [23] used an inspection policy for the batch not for a single item. Wang and Sheu [24] discussed a deteriorating production system with product inspection policy. In addition, production-maintenance policy is also discussed in their model. Wang [25] optimized the production run length and product inspection policy by obtaining an efficient solution procedure. Ben-Daya and Noman [26] formulated an integrated inventory model based on the assumption that a lot is received, buyer uses some special type of inspection policies. The fraction nonconforming is considered to be a random variable which follows a beta distribution. Konstantaras et al. [27] deduced a classical economic order quantity model with the assumption that all received items may be damaged due to transportation or production condition while screening is usually a manual task performed by inspectors which may improve with learning. Yoo et al. [28] addressed an imperfect production and inspection system with customer return and defective disposal. They considered production and inspection quality investment with all quality costs. They assumed Type I and Type II inspection error proportions which minimize the total quality cost and maximize the total profit. Recently, Sarkar and Saren [29] extended an economic production quantity model with warranty, inspections, and inspection errors.

Supply chain defines a management linking the organizations in order to fulfill demand across the whole chain as efficiently as possible. It generally minimizes transportation costs of inventories and manages inventories needed across the supply chain. The aim of supply chain is to satisfy all customers with more facilities, less cost, and time, as well as good quality. Asghari [30] examined the applicability of numerous measures and metrics in a multiobjective optimization problem of supply chain network design to allocate customers' orders. He determined important aspects 
of strategic planning of manufacturing in a supply chain model. In Lin et al's [31] model, a hybrid approach, including applied interpretive structural modeling to build a hierarchical structure, and application of analytic network process to examine dependence relations are discussed. In addition, their model used fuzzy set theory to analyze linguistic preferences. They also provided that the financial aspect and life cycle assessment are the most essential performance and weighted criteria. Watanabe and Kusukawa [32] generated an optimal operational policy for both decentralized GSC (DGSC) and an integrated GSC (IGSC). They described that a retailer pays an incentive for collection of used items from customers and formulates optimal order quantity of a single product under uncertainty in product demand. In their model, some mathematical models are observed to obtain collection incentive of used products, lower limit of quality level for recycling affectability. Chen [33] produced how green operations affect firms environmental performance with green innovation. His model determined the positive relationships existing among green operations, green innovation, and environmental performance. Kusukawa [34] deduced decision-making approaches for two situations which made a decentralized supply chain (DSC). Decentralized supply chain (DSC) maximizes the retailers profit and an integrated supply chain (ISC) is used to increase the whole systems profit. On the other hand, supply chain coordination is established to set the unit wholesale price at each order time with Nash bargaining solutions. Watanabe and Kusukawa [35] studied a dual-sourcing supply chain (DSSC) in which two scenarios of product's demand are considered as known demand distribution and known mean and variance of demand. They analyzed an optimal ordering policy under DSSC to increase the total expected profit and an optimal ordering policy under the integrated DSSC to maximize the whole systems total expected profit. See Table 1 for the contribution of several authors.

This study is considered to discuss the effect of carbon emission cost reduction during transportation in industry sector. During transporting items, fixed and variable carbon emission costs for both vendor and buyer are used in this paper. It is assumed that the vendor's setup cost is variable and delivery lot sizes are unequal and variable. After receiving the lot, the buyer conducts an inspection procedure and defective items are returned to vendor for reworking operation. The main purpose for developing this model is to reduce the carbon emission cost for vendor-buyer system. This paper continues with mathematical model in Section 2. Section 3 presents solution methodology of this model. A numerical example and sensitivity analysis are discussed in Section 4. Finally, conclusions are given in Section 5.

\section{Mathematical Model}

The following notations are used to develop the model.

Decision Variables

$A_{1}$ : vendor's setup cost (\$/setup); $\lambda$ : increasing rate of shipment lot size (positive integer);

$n$ : number of shipments per batch production (positive integer);

q: first delivery lot size of each batch during production (units).

\section{Parameters}

$D$ : demand rate (units/year);

$P$ : production rate (units/year);

$H_{v}$ : vendor's holding cost per unit per year (\$/unit/year);

$S_{v}$ : vendor's fixed carbon emission cost per delivery (\$/delivery)

$Y_{v}$ : vendor's variable carbon emission cost per unit (\$/unit);

$A_{2}$ : buyer's ordering cost per order (\$/order);

$A_{3}$ : buyer's shipment cost per shipment (\$/shipment);

$S$ : buyer's inspection cost per unit (\$/unit);

$x$ : inspection rate (units/year);

$S_{b}$ : buyer's fixed carbon emission cost per shipment (\$/shipment);

$Y_{b}$ : buyer's variable carbon emission cost per unit (\$/unit);

$H_{1}$ : buyer's holding cost for nondefective items (\$/unit/year);

$\mathrm{H}_{2}$ : buyer's holding cost for defective items (\$/unit/year);

$Y_{r}$ : vendor's rework cost per unit (\$/unit);

$\gamma$ : defective rate;

$V_{h}$ : total holding cost for vendor (\$/year);

$B_{n}$ : total holding cost of nondefective items for buyer (\$/year);

$B_{d}$ : total holding cost of defective items for buyer (\$/year);

$B_{c}$ : total carbon emission cost for buyer (\$/year);

$V_{c}$ : total carbon emission cost for vendor (\$/year);

$T_{B}$ : total cost for buyer ( $\$ /$ year);

$T_{V}$ : total cost for vendor (\$/year);

JTC: joint total cost for vendor-buyer system (\$/year).

To construct this model, the following assumptions are utilized.

(1) A single-vendor single-buyer model is considered for a single type of product.

(2) Whenever the buyer places an order, the vendor shipped the lot size in an unequal sized delivery. Delivery rate for lot size is assumed as $\lambda$. 
TABLE 1: Contribution of the different authors.

\begin{tabular}{|c|c|c|c|c|c|}
\hline Author(s) & $\begin{array}{l}\text { Setup cost } \\
\text { reduction }\end{array}$ & $\begin{array}{c}\text { Unequal delivery } \\
\text { lot size }\end{array}$ & Carbon emission cost & Inspection policy & $\begin{array}{l}\text { Supply chain } \\
\text { management }\end{array}$ \\
\hline Nag and Parikh [1] & & & $\sqrt{ }$ & & \\
\hline Butler et al. [2] & & & $\sqrt{ }$ & & \\
\hline Ma et al. [3] & & & $\sqrt{ }$ & & \\
\hline Wygonik and Goodchild [4] & & & $\sqrt{ }$ & & \\
\hline Hua et al. [5] & & & $\sqrt{ }$ & & \\
\hline Bachmann and Van Der Kamp [6] & & & $\sqrt{ }$ & & \\
\hline Zhang et al. [7] & & & $\sqrt{ }$ & & \\
\hline Hong et al. [8] & $\sqrt{ }$ & $\sqrt{ }$ & & & \\
\hline Ouyang et al. [9] & $\sqrt{ }$ & & & & \\
\hline Chuang et al. [10] & $\sqrt{ }$ & & & & \\
\hline Hou [11] & $\sqrt{ }$ & & & & \\
\hline Sarkar and Majumder [12] & $\sqrt{ }$ & & & & $\sqrt{ }$ \\
\hline Diaby et al. [13] & $\sqrt{ }$ & & & & \\
\hline Sarkar and Moon [14] & $\sqrt{ }$ & & & & \\
\hline Sarkar et al. [15] & $\sqrt{ }$ & & & & \\
\hline Goyal and Szendrovits [16] & & $\sqrt{ }$ & & & \\
\hline Hoque and Kingsman [17] & & $\sqrt{ }$ & & & \\
\hline Bogaschewsky et al. [18] & & $\sqrt{ }$ & & & \\
\hline Siajadi et al. [19] & & $\sqrt{ }$ & & & \\
\hline Zhou and Wang [20] & & $\sqrt{ }$ & & & \\
\hline Hoque [21] & & $\sqrt{ }$ & & & \\
\hline Hariga et al. [22] & & $\sqrt{ }$ & & & \\
\hline Wang and Sheu [23] & & & & $\sqrt{ }$ & \\
\hline Wang and Sheu [24] & & & & $\sqrt{ }$ & \\
\hline Wang [25] & & & & $\sqrt{ }$ & \\
\hline Ben-Daya and Noman [26] & & & & $\sqrt{ }$ & \\
\hline Konstantaras et al. [27] & & & & $\sqrt{ }$ & \\
\hline Yoo et al. [28] & & & & $\sqrt{ }$ & \\
\hline Sarkar and Saren [29] & & & & $\sqrt{ }$ & \\
\hline Asghari [30] & & & & & $\sqrt{ }$ \\
\hline Lin et al. [31] & & & & & $\sqrt{ }$ \\
\hline Watanabe and Kusukawa [32] & & & & & $\sqrt{ }$ \\
\hline Chen [33] & & & & & $\sqrt{ }$ \\
\hline Kusukawa [34] & & & & & $\sqrt{ }$ \\
\hline Watanabe and Kusukawa [35] & & & & & $\sqrt{ }$ \\
\hline This paper & $\sqrt{ }$ & $\sqrt{ }$ & $\sqrt{ }$ & $\sqrt{ }$ & $\sqrt{ }$ \\
\hline
\end{tabular}

(3) Vendor's setup cost is taken as variable instead of taking as constant. This setup cost is reduced by using an investment to decrease total cost function of vendor.

(4) After receiving each lot, the buyer commences an inspection process to detect the defective items. While the next lot has been received from the vendor, the buyer sent back all defective items of previous lot to vendor for reworking procedure.

(5) Carbon emission costs for both vendor and buyer are included during transporting lots. Two types of carbon emission costs, that is, fixed and variable, are considered.

(6) Demand is assumed to be deterministic.

(7) Shortages are not considered in this model as production rate is greater than demand rate; that is, $P>D$.

(8) Lead time is assumed to be negligible.

Buyer orders a lot of items with the ordering cost $A_{2}$ per order. On the other hand, vendor produced lot of products with production rate $P$ per year and variable setup cost $A_{1}$. Later, vendor transported first lot size $q$ units with delivery 


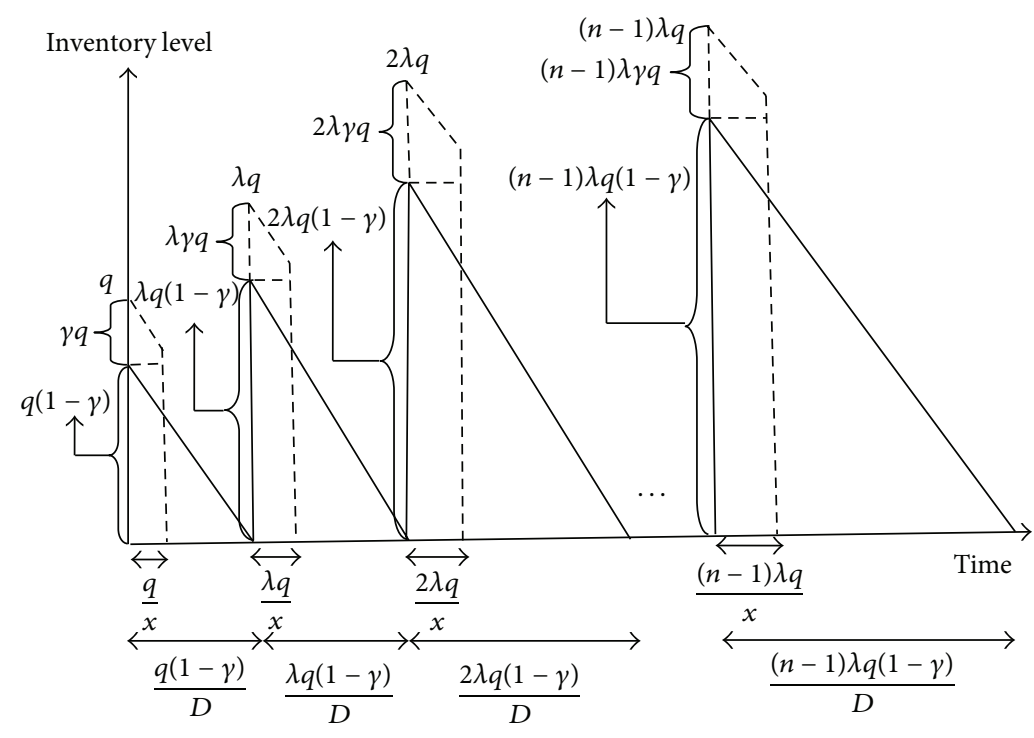

Figure 1: Buyer's inventory model.

cost $A_{3}$. In every production cycle, vendor shipped lot of orders in $n$ times. After the delivery of first $q$ items, the quantity has been shifted from vendor to buyer on $j$ th delivery which is $(j-1) \lambda q, j>1$. During transporting items, vendor incurs fixed carbon emission cost $S_{v}$ and variable carbon emission cost $Y_{v}$ due to variable lot size of delivery. After getting the lot, the buyer starts an inspection process with inspection rate $x$ and incurs some cost $S$. In every lot, the rate of defective item is $\gamma$. While the inspection process is finished, nondefective and defective items are classified. Buyer holds nondefective items with the holding cost $H_{1}$ and sends back defective items to vendor for reworking process. Throughout the transporting of these defective items, buyer incurs fixed and variable carbon emission costs as $S_{b}$ per shipment and $Y_{b}$ per unit product.

2.1. Buyer's Mathematical Model. Using SSMD policy, vendor sends ordered lot size in $n$ times for each production cycle. After the delivery of lot size $q$, the quantity has been shifted from vendor to buyer on $j$ th delivery as $(j-1) \lambda q, j>1$; that is, second shipment lot size is $\lambda q$. After that, delivery lot sizes are $2 \lambda q, 3 \lambda q$, and so on.

Therefore, the production batch which transported from vendor to buyer is obtained by summing the total of shipment lots as follows:

$$
q+\lambda q+2 \lambda q+\cdots+(n-1) \lambda q=q+\frac{\lambda q n(n-1)}{2} .
$$

The number of production cycles is calculated by dividing the demand with the production batch. That is,

$$
\frac{D}{q+\lambda(n(n-1) / 2) q}=\frac{2 D}{2 q+q \lambda n(n-1)} \text {. }
$$

Buyer's total ordering cost for entire production cycle is

$$
A_{2}\left(\frac{2 D}{2 q+\lambda q n(n-1)}\right) \text {. }
$$

In similar manner, buyer's total delivery cost equals

$$
n A_{3}\left(\frac{2 D}{2 q+\lambda q n(n-1)}\right) \text {. }
$$

After receiving products from vendor, buyer starts an inspection process for separating the defective items.

Hence, buyer's total inspection cost during product inspection is $S D$.

The total number of nondefective items for each production cycle is obtained by the area of the triangle given in Figure 1; that is,

$$
\begin{aligned}
\frac{1}{2} q(1-\gamma) \frac{(1-\gamma) q}{D}+\frac{1}{2} \lambda q(1-\gamma) \frac{\lambda(1-\gamma) q}{D}+\cdots \\
+\frac{1}{2}(n-1) \lambda q(1-\gamma) \frac{(n-1) \lambda(1-\gamma) q}{D} \\
=\frac{1}{2} \frac{q^{2}(1-\gamma)^{2}}{D}\left[1+\frac{\lambda^{2} n(n-1)(2 n-1)}{6}\right] .
\end{aligned}
$$

Therefore, the total holding cost of nondefective items $B_{n}$ is obtained by multiplying all nondefective items with production cycle

$$
\begin{aligned}
& B_{n}=H_{1}\left[\frac{1}{2} \frac{q^{2}(1-\gamma)^{2}}{D}\left(1+\frac{\lambda^{2} n(n-1)(2 n-1)}{6}\right)\right] \\
& \cdot {\left[\frac{2 D}{2 q+\lambda q n(n-1)}\right]=H_{1}\left[\left(\frac{q(1-\gamma)^{2}}{2+\lambda n(n-1)}\right)\right.} \\
&\left.\cdot\left(1+\frac{\lambda^{2} n(n-1)(2 n-1)}{6}\right)\right] .
\end{aligned}
$$


The total number of defective items is formulated from the parallelogram presented in Figure 1; that is,

$$
\begin{gathered}
q \gamma \frac{q}{x}+\lambda q \gamma \frac{\lambda q}{x}+\cdots+\lambda(n-1) q \gamma \frac{(n-1) \lambda q}{x} \\
=\frac{q^{2} \gamma}{x}\left(1+\frac{\lambda^{2} n(n-1)(2 n-1)}{6}\right) .
\end{gathered}
$$

The total holding cost of defective items $B_{d}$ is determined by multiplying all defective items with production cycle

$$
\begin{aligned}
B_{d} & =H_{2}\left[\frac{q^{2} \gamma}{x}\left(1+\frac{\lambda^{2} n(n-1)(2 n-1)}{6}\right)\right] \\
& \cdot\left[\frac{2 D}{2 q+\lambda q n(n-1)}\right] \\
= & H_{2}\left[\frac{2 D q \gamma}{x(2+\lambda n(n-1))}(1\right. \\
& \left.\left.+\frac{\lambda^{2} n(n-1)(2 n-1)}{6}\right)\right] .
\end{aligned}
$$

During transporting of products, buyer's incurs two types of carbon emission costs, that is, fixed and variable.

Buyer's fixed carbon emission cost can be calculated for the entire production cycle as $n S_{b}[2 D /(2 q+\lambda q n(n-1))]$ and variable carbon emission cost is obtained by multiplying $Y_{b}$ with demand $D$, that is, $Y_{b} D$.

Hence, total carbon emission cost for the buyer by assuming fixed and variable carbon emission costs is

$$
B_{c}=n S_{b}\left[\frac{2 D}{2 q+\lambda q n(n-1)}\right]+Y_{b} D .
$$

Total inventory cost for buyer can be calculated by adding ordering cost, delivery cost, inspection cost, carbon emission cost, holding cost of nondefective items, and holding cost of defective items as follows:

$$
\begin{aligned}
& T_{B}(n, q, \lambda)=A_{2}\left(\frac{2 D}{2 q+\lambda q n(n-1)}\right) \\
& +n A_{3}\left(\frac{2 D}{2 q+\lambda q n(n-1)}\right)+S D+Y_{b} D \\
& +2 n S_{b}\left(\frac{D}{2 q+\lambda q n(n-1)}\right) \\
& +H_{1}\left[\left(\frac{q(1-\gamma)^{2}}{2+\lambda n(n-1)}\right)(1\right. \\
& \left.\left.+\frac{\lambda^{2} n(n-1)(2 n-1)}{6}\right)\right] \\
& +H_{2}\left[\frac{2 D q \gamma}{x(2+\lambda n(n-1))}(1\right. \\
& \left.\left.+\frac{\lambda^{2} n(n-1)(2 n-1)}{6}\right)\right] .
\end{aligned}
$$

2.2. Vendor's Mathematical Model. The number of production cycles is

$$
\frac{D}{q+\lambda(n(n-1) / 2) q}=\frac{2 D}{2 q+q \lambda n(n-1)}
$$

and setup cost is $A_{1}$. 1)q))

Hence, vendor's total setup cost is $A_{1}(2 D /(2 q+\lambda n(n-$

Vendor's rework cost for retread defective items is given by $Y_{r} \gamma D$, where $\gamma$ is the defective rate.

The total stock in the production system is

$$
\frac{D q}{P}+(P-D)\left(\frac{2 q+\lambda n(n-1) q}{4 P}\right) .
$$

The average vendor stock can be obtained by subtracting the total number of nondefective and defective items from vendor's total stock; that is,

$$
\begin{gathered}
\frac{D q}{P}+(P-D)\left(\frac{2 q+\lambda n(n-1) q}{4 P}\right) \\
-\left(\frac{q(1-\gamma)^{2}[2+\lambda n(n-1)]}{4}\right) \\
-\left(\frac{q \gamma D[2+\lambda n(n-1)]}{2 x}\right) .
\end{gathered}
$$

The total holding cost for the vendor is

$$
\begin{aligned}
V_{h} & =H_{v}\left[\frac{D q}{P}+(P-D)\left(\frac{2 q+\lambda n(n-1) q}{4 P}\right)\right. \\
& -\left(\frac{q(1-\gamma)^{2}[2+\lambda n(n-1)]}{4}\right) \\
& \left.-\left(\frac{q \gamma D[2+\lambda n(n-1)]}{2 x}\right)\right] .
\end{aligned}
$$

In a similar manner for buyer's case, carbon emission cost can be observed for the vendor.

The total carbon emission cost for vendor is determined by adding fixed and variable carbon emission costs. That is,

$$
V_{c}=n \frac{2 S_{v} D}{2 q+\lambda n(n-1) q}+Y_{v} \gamma D .
$$

If $I_{A_{1}}$ is an investment for the setup cost reduction, then it can be expressed as

$$
\begin{aligned}
& I_{A_{1}}=R \ln \left(\frac{A_{0}}{A_{1}}\right)=R\left(\ln A_{0}-\ln A_{1}\right) \\
& \qquad \text { for } 0<A_{1} \leq A_{0},
\end{aligned}
$$

where $A_{0}$ is the original setup cost, $R=1 / \delta$, and $\delta$ is the percentage decrease in $A_{1}$ per dollar increase in $I_{A_{1}}$.

The total inventory cost for the vendor can be calculated by adding setup cost, rework cost, fixed and variable carbon 
emission cost, holding cost, and investment for the setup cost reduction

$$
\begin{aligned}
& T_{V}\left(n, q, \lambda, A_{1}\right)=A_{1}\left(\frac{2 D}{2 q+\lambda n(n-1) q}\right)+Y_{r} \gamma D \\
& +\frac{2 n S_{v} D}{2 q+\lambda n(n-1) q}+Y_{v} \gamma D+H_{v}\left[\frac{D q}{P}\right. \\
& +(P-D)\left(\frac{2 q+\lambda n(n-1) q}{4 P}\right) \\
& -\left(\frac{q(1-\gamma)^{2}[2+\lambda n(n-1)]}{4}\right) \\
& \left.-\left(\frac{q \gamma D[2+\lambda n(n-1)]}{2 x}\right)\right]+\alpha R\left(\ln A_{0}-\ln A_{1}\right)
\end{aligned}
$$

where $\alpha$ is the annual fractional cost of the capital investment.

Therefore, the joint total cost for vendor-buyer system is formulated by

$$
\begin{aligned}
& \operatorname{JTC}\left(n, q, \lambda, A_{1}\right)=\left(A_{1}+A_{2}+n A_{3}+n S_{b}+n S_{v}\right) \\
& \cdot\left(\frac{2 D}{2 q+\lambda n(n-1) q}\right)+\left(S+Y_{b}+Y_{r} \gamma+Y_{v} \gamma\right) D \\
& +\alpha R\left(\ln A_{0}-\ln A_{1}\right)+(1 \\
& \left.+\frac{\lambda^{2} n(n-1)(2 n-1)}{6}\right) \frac{q}{[2+\lambda n(n-1)]}\left(\frac{2 D \gamma}{x} H_{2}\right. \\
& \left.+(1-\gamma)^{2} H_{1}\right)+H_{v} q\left[\frac{D}{P}\right. \\
& \left.+(2+\lambda n(n-1))\left(\frac{(P-D)}{4 P}-\frac{(1-\gamma)^{2}}{4}-\frac{\gamma D}{2 x}\right)\right] .
\end{aligned}
$$

\section{Solution Methodology}

The necessary conditions to minimize the joint total cost for vendor-buyer system JTC are $\partial \mathrm{JTC} / \partial n=0, \partial \mathrm{JTC} / \partial q=0$, $\partial \mathrm{JTC} / \partial \lambda=0$, and $\partial \mathrm{JTC} / \partial A_{1}=0$.
The first order partial derivative of joint total cost for vendor-buyer system JTC with respect to the number of shipments per batch production $n$ is

$$
\begin{aligned}
& \frac{\partial \mathrm{JTC}}{\partial n} \\
& =\frac{2 D Y}{2 q+\lambda n(n-1) q} \\
& \quad-\frac{2 D \lambda q(2 n-1)}{(2 q+\lambda n(n-1) q)^{2}}\left(A_{1}+A_{2}+n Y\right) \\
& \quad+\frac{q X \lambda^{2}}{6(2+\lambda n(n-1))}\left(6 n^{2}-6 n+1\right) \\
& \quad-\frac{q \lambda X(2 n-1)}{(2+\lambda n(n-1))^{2}}\left(1+\frac{\lambda^{2} n(n-1)(2 n-1)}{6}\right) \\
& =\phi(n) .
\end{aligned}
$$

The optimal value of $n$ (say $n^{*}$ ) will be obtained if it satisfies the equation $\phi\left(n^{*}\right)=0$, where $\partial \mathrm{JTC} / \partial n=\phi(n)$.

Now, the first order partial derivative of joint total cost for vendor-buyer system JTC regarding to first delivery lot size of each batch during production $q$ is

$$
\begin{aligned}
& \frac{\partial \mathrm{JTC}}{\partial q} \\
& =\frac{2 D\left(A_{1}+A_{2}+n Y\right)}{q^{2}(2+\lambda n(n-1))} \\
& \quad-\frac{X}{(2+\lambda n(n-1))}\left(1+\frac{\lambda^{2} n(n-1)(2 n-1)}{6}\right) \\
& \quad+H_{v}\left[\frac{D}{P}+(2+\lambda n(n-1)) E\right] .
\end{aligned}
$$

(See the Appendix for the values of $X, Y$, and $E$.) By equating $\partial \mathrm{JTC} / \partial q=0$, the optimal value of $q\left(\right.$ say $\left.q^{*}\right)$ is as

$$
q^{*}=\sqrt{\frac{2 D\left(A_{1}+A_{2}+n Y\right)}{\left[X\left(1+\lambda^{2} n(n-1)(2 n-1) / 6\right)+H_{v}(2+\lambda n(n-1))(D / P+(2+\lambda n(n-1)) E)\right]}} .
$$

Now, the first order partial derivative of joint total cost for vendor-buyer system JTC with respect to the increasing rate of shipment lot size $\lambda$ is

$$
\frac{\partial \mathrm{JTC}}{\partial \lambda}=\lambda^{2}\left(\frac{5 n X(n-1)(2 n-1)}{6}+H_{v} E n^{2}(n-1)^{2}\right)
$$

$$
\begin{aligned}
& +\lambda\left(2 X(2 n-1)+4 H_{v} E n(n-1)\right) \\
& +\left(4 H_{v} E-X-\frac{2 D\left(A_{1}+A_{2}+n Y\right)}{q^{2}}\right) .
\end{aligned}
$$


Similar to $n$, in this case the optimal value of $\lambda$ (say $\left.\lambda^{*}\right)$ can be obtained if it satisfies $\Psi\left(\lambda^{*}\right)=0$, where $\Psi(\lambda)=\partial$ JTC $/ \partial \lambda$.

Now, the first order partial derivative of joint total cost for vendor-buyer system JTC with respect to vendor's setup cost $A_{1}$ is

$$
\frac{\partial \mathrm{JTC}}{\partial A_{1}}=\frac{2 D}{2 q+\lambda n(n-1) q}-\frac{\alpha R}{A_{1}} .
$$

From the equation $\partial \mathrm{JTC} / \partial A_{1}=0$, the optimal value of $A_{1}\left(\right.$ say $\left.A_{1}^{*}\right)$ will be

$$
A_{1}^{*}=\frac{\alpha R(2 q+\lambda n(n-1) q)}{2 D} .
$$

Lemma 1. The joint total cost always contain the global minimum solution as the Hessian matrix for $\operatorname{JTC}\left(n, q, \lambda, A_{1}\right)$ is always positive definite at the optimal values $\left(n^{*}, q^{*}, \lambda^{*}, A_{1}^{*}\right)$.

Proof. The first order partial derivatives of joint total cost for vendor-buyer system JTC with respect to $n, q, \lambda$, and $A_{1}$ are as follows:

$$
\begin{aligned}
& \frac{\partial \mathrm{JTC}}{\partial n}=\frac{1}{2+\lambda n(n-1)}\left[\frac{2 D Y}{q}\right. \\
& \left.+\frac{q X \lambda^{2}\left(6 n^{2}-6 n+1\right)}{6}\right] \\
& \quad-\frac{(2 n-1)}{(2+\lambda n(n-1))^{2}}\left[\left(A_{1}+A_{2}+n Y\right)\right. \\
& \left.\quad+q \lambda X\left(1+\frac{\lambda^{2} n(n-1)(2 n-1)}{6}\right)\right], \\
& \frac{\partial \mathrm{JTC}}{\partial q}=\frac{2 D\left(A_{1}+A_{2}+n Y\right)}{q^{2}(2+\lambda n(n-1))}-\frac{X}{(2+\lambda n(n-1))}(1 \\
& \left.\quad+\frac{\lambda^{2} n(n-1)(2 n-1)}{6}\right)+H_{v}\left[\frac{D}{P}\right. \\
& \left.\quad+\frac{2 D\left(A_{1}+A_{2}+n Y\right)}{q^{2}}\right), \\
& \frac{\partial \mathrm{JTC}}{\partial \lambda}=\lambda^{2}\left(\frac{5 n X(n-1)(2 n-1)}{6}+H_{v} E n^{2}(n-1)^{2}\right)
\end{aligned}
$$

The Hessian matrix at the optimal values is given as

$$
\begin{aligned}
H_{i i} & {\left[\begin{array}{llll}
\frac{\partial^{2} \mathrm{JTC}(\cdot)}{\partial A_{1}^{* 2}} & \frac{\partial^{2} \mathrm{JTC}(\cdot)}{\partial A_{1}^{*} \partial q^{*}} & \frac{\partial^{2} \mathrm{JTC}(\cdot)}{\partial A_{1}^{*} \partial n^{*}} & \frac{\partial^{2} \mathrm{JTC}(\cdot)}{\partial A_{1}^{*} \partial \lambda^{*}} \\
\frac{\partial^{2} \mathrm{JTC}(\cdot)}{\partial q^{*} \partial A_{1}^{*}} & \frac{\partial^{2} \mathrm{JTC}(\cdot)}{\partial q^{* 2}} & \frac{\partial^{2} \mathrm{JTC}(\cdot)}{\partial q^{*} \partial n^{*}} & \frac{\partial^{2} \mathrm{JTC}(\cdot)}{\partial q^{*} \partial \lambda^{*}} \\
\frac{\partial^{2} \mathrm{JTC}(\cdot)}{\partial n^{*} \partial A_{1}^{*}} & \frac{\partial^{2} \mathrm{JTC}(\cdot)}{\partial n^{*} \partial q^{*}} & \frac{\partial^{2} \mathrm{JTC}(\cdot)}{\partial n^{* 2}} & \frac{\partial^{2} \mathrm{JTC}(\cdot)}{\partial n^{*} \partial \lambda^{*}} \\
\frac{\partial^{2} \mathrm{JTC}(\cdot)}{\partial \lambda^{*} \partial A_{1}^{*}} & \frac{\partial^{2} \mathrm{JTC}(\cdot)}{\partial \lambda^{*} \partial q^{*}} & \frac{\partial^{2} \mathrm{JTC}(\cdot)}{\partial \lambda^{*} \partial n^{*}} & \frac{\partial^{2} \mathrm{JTC}(\cdot)}{\partial \lambda^{* 2}}
\end{array}\right], }
\end{aligned}
$$

where $\operatorname{JTC}(\cdot)=\operatorname{JTC}\left(n^{*}, q^{*}, \lambda^{*}, A_{1}^{*}\right)$.

The second order partial derivatives at the optimal values are given by

$$
\begin{aligned}
& \frac{\partial^{2} \operatorname{JTC}\left(n^{*}, q^{*}, \lambda^{*}, A_{1}^{*}\right)}{\partial A_{1}^{* 2}}=\frac{\alpha R}{A_{1}^{2}}, \\
& \frac{\partial^{2} \operatorname{JTC}\left(n^{*}, q^{*}, \lambda^{*}, A_{1}^{*}\right)}{\partial q^{* 2}}=\frac{4 D\left(A_{1}+A_{2}+n Y\right)}{q^{3}[2+\lambda n(n-1)]}, \\
& \frac{\partial^{2} \operatorname{JTC}\left(n^{*}, q^{*}, \lambda^{*}, A_{1}^{*}\right)}{\partial \lambda^{* 2}}=2 \lambda\left(\frac{5 n X(n-1)(2 n-1)}{6}\right. \\
& \left.+H_{v} E n^{2}(n-1)^{2}\right)+[2 X(2 n-1) \\
& \left.+4 H_{v} \operatorname{En}(n-1)\right], \\
& \frac{\partial^{2} \operatorname{JTC}\left(n^{*}, q^{*}, \lambda^{*}, A_{1}^{*}\right)}{\partial n^{* 2}} \\
& =\frac{\lambda^{2}(2 n-1)^{2}}{(2+\lambda n(n-1))^{3}}\left[\frac{4 D\left(A_{1}+A_{2}+n Y\right)}{q^{2}}\right. \\
& \left.+2 q^{3} X\left(1+\frac{\lambda^{2} n(n-1)(2 n-1)}{6}\right)\right] \\
& -\frac{\lambda}{(2+\lambda n(n-1))^{2}}\left[\frac{4 D Y(2 n-1)}{q}\right. \\
& +\frac{4 D\left(A_{1}+A_{2}+n Y\right)}{q} \\
& +2 q X\left(1+\frac{\lambda^{2} n(n-1)(2 n-1)}{6}\right) \\
& \left.+q \lambda X(2 n-1) \frac{\left(6 n^{2}-6 n+1\right)}{6}(\lambda+1)\right], \\
& \frac{\partial^{2} \operatorname{JTC}\left(n^{*}, q^{*}, \lambda^{*}, A_{1}^{*}\right)}{\partial A_{1}^{*} \partial q^{*}}=\frac{\partial^{2} \operatorname{JTC}\left(n^{*}, q^{*}, \lambda^{*}, A_{1}^{*}\right)}{\partial q^{*} \partial A_{1}^{*}} \\
& =-\frac{2 D}{q^{2}[2+\lambda n(n-1)]},
\end{aligned}
$$




$$
\begin{array}{lc}
\frac{\partial^{2} \mathrm{JTC}\left(n^{*}, q^{*}, \lambda^{*}, A_{1}^{*}\right)}{\partial A_{1}^{*} \partial n^{*}}=\frac{\partial^{2} \mathrm{JTC}\left(n^{*}, q^{*}, \lambda^{*}, A_{1}^{*}\right)}{\partial n^{*} \partial A_{1}^{*}} & \text { where } \\
=-\frac{2 D \lambda(2 n-1)}{q[2+\lambda n(n-1)]^{2}}, & x_{1}=\frac{\partial^{2} \mathrm{JTC}(\cdot)}{\partial A_{1}^{* 2}}=\frac{\alpha R}{A_{1}^{2}}>0, \\
\frac{\partial^{2} \operatorname{JTC}\left(n^{*}, q^{*}, \lambda^{*}, A_{1}^{*}\right)}{\partial A_{1}^{*} \partial \lambda^{*}}=\frac{\partial^{2} \operatorname{JTC}\left(n^{*}, q^{*}, \lambda^{*}, A_{1}^{*}\right)}{\partial \lambda^{*} \partial A_{1}^{*}} & y_{1}=\frac{\partial^{2} \mathrm{JTC}(\cdot)}{\partial q^{* 2}}=\frac{4 D\left(A_{1}+A_{2}+n A_{3}+n S_{b}+n S_{v}\right)}{q^{3}[2+\lambda n(n-1)]^{2}} \\
=-\frac{2 D n(n-1)}{q[2+\lambda n(n-1)]^{2}}, & >0, \\
\frac{\partial^{2} \operatorname{JTC}\left(n^{*}, q^{*}, \lambda^{*}, A_{1}^{*}\right)}{\partial q^{*} \partial n^{*}}=\frac{\partial^{2} \mathrm{JTC}\left(n^{*}, q^{*}, \lambda^{*}, A_{1}^{*}\right)}{\partial n^{*} \partial q^{*}} & z_{1}=\frac{2 D}{q^{2}[2+\lambda n(n-1)]}>0 .
\end{array}
$$$$
=\frac{1}{2+\lambda n(n-1)}\left[\frac{X \lambda^{2}\left(6 n^{2}-6 n+1\right)}{6}-\frac{2 D Y}{q^{2}}\right]
$$$$
-\frac{(2 n-1) \lambda X}{(2+\lambda n(n-1))^{2}}\left(1+\frac{\lambda^{2} n(n-1)(2 n-1)}{6}\right),
$$$$
\frac{\partial^{2} \operatorname{JTC}\left(n^{*}, q^{*}, \lambda^{*}, A_{1}^{*}\right)}{\partial n^{*} \partial \lambda^{*}}=\frac{\partial^{2} \operatorname{JTC}\left(n^{*}, q^{*}, \lambda^{*}, A_{1}^{*}\right)}{\partial \lambda^{*} \partial n^{*}}
$$$$
=\lambda^{2}\left(\frac{5 X\left(6 n^{2}-6 n+1\right)}{6}\right.
$$$$
\left.+H_{v} E\left(4 n^{3}-6 n^{2}+2 n\right)\right)+\lambda(4 X
$$$$
\left.+4 H_{v} E(2 n-1)\right)-\frac{2 D Y}{q^{2}},
$$$$
\frac{\partial^{2} \operatorname{JTC}\left(n^{*}, q^{*}, \lambda^{*}, A_{1}^{*}\right)}{\partial q^{*} \partial \lambda^{*}}=\frac{\partial^{2} \operatorname{JTC}\left(n^{*}, q^{*}, \lambda^{*}, A_{1}^{*}\right)}{\partial \lambda^{*} \partial q^{*}}
$$$$
=\frac{4 D\left(A_{1}+A_{2}+n Y\right)}{q^{3}} \text {. }
$$

At the optimal values, the principal minors are

$$
\operatorname{det}\left(H_{11}\right)=\operatorname{det}\left(\frac{\partial^{2} \mathrm{JTC}(\cdot)}{\partial A_{1}^{* 2}}\right)=\frac{\alpha R}{A_{1}^{2}}>0
$$

As all the terms, $\alpha, R$, and $A_{1}$, are positive, the first principal minor is obviously greater than zero.

Now,

$$
\operatorname{det}\left(H_{22}\right)=\left|\begin{array}{cc}
\frac{\partial^{2} \mathrm{JTC}(\cdot)}{\partial A_{1}^{* 2}} & \frac{\partial^{2} \mathrm{JTC}(\cdot)}{\partial A_{1}^{*} \partial q^{*}} \\
\frac{\partial^{2} \mathrm{JTC}(\cdot)}{\partial q^{*} \partial A_{1}^{*}} & \frac{\partial^{2} \mathrm{JTC}(\cdot)}{\partial q^{* 2}}
\end{array}\right|=x_{1} y_{1}-z_{1}^{2},
$$

It is assumed that

$$
\xi=\frac{\alpha R}{A_{1}^{2}}-\frac{2 D}{q^{2}[2+\lambda n(n-1)]} .
$$

Now,

$$
\xi>0 \quad \text { as } \frac{\alpha R}{A_{1}^{2}}>\frac{2 D}{q^{2}[2+\lambda n(n-1)]}>0 .
$$

On the other hand, $x_{1}=\operatorname{det}\left(H_{11}\right)>0$.

Therefore, $x_{1}-z_{1}>0$.

Similarly, it can be obtained that $y_{1}>z_{1}$.

From the two conditions $x_{1}>z_{1}$ and $y_{1}>z_{1}$, one can obtain that $x_{1} y_{1}-z_{1}^{2}>0$ which implies $\operatorname{det}\left(H_{22}\right)>0$.

Now,

$$
\begin{aligned}
\operatorname{det}\left(H_{33}\right) & =\left|\begin{array}{lll}
\frac{\partial^{2} \mathrm{JTC}(\cdot)}{\partial A_{1}^{* 2}} & \frac{\partial^{2} \mathrm{JTC}(\cdot)}{\partial A_{1}^{*} \partial q^{*}} & \frac{\partial^{2} \mathrm{JTC}(\cdot)}{\partial A_{1}^{*} \partial n^{*}} \\
\frac{\partial^{2} \mathrm{JTC}(\cdot)}{\partial q^{*} \partial A_{1}^{*}} & \frac{\partial^{2} \mathrm{JTC}(\cdot)}{\partial q^{* 2}} & \frac{\partial^{2} \mathrm{JTC}(\cdot)}{\partial q^{*} \partial n^{*}} \\
\frac{\partial^{2} \operatorname{JTC}(\cdot)}{\partial n^{*} \partial A_{1}^{*}} & \frac{\partial^{2} \mathrm{JTC}(\cdot)}{\partial n^{*} \partial q^{*}} & \frac{\partial^{2} \mathrm{JTC}(\cdot)}{\partial n^{* 2}}
\end{array}\right| \\
& =u^{2} x_{1}+\zeta+w\left|H_{22}\right|,
\end{aligned}
$$

where

$$
\begin{aligned}
w & =\frac{\partial^{2} \operatorname{JTC}(\cdot)}{\partial n^{* 2}} \\
u^{2} & =\left[\frac{(2 n-1) \lambda X}{(2+\lambda n(n-1))^{2}}\left(1+\frac{\lambda^{2} n(n-1)(2 n-1)}{6}\right)\right. \\
& -\frac{1}{2+\lambda n(n-1)}\left(\frac{X \lambda^{2}\left(6 n^{2}-6 n+1\right)}{6}\right. \\
& \left.\left.-\frac{2 D Y}{q^{2}}\right)\right]^{2}
\end{aligned}
$$


Now,

$$
\begin{aligned}
& \zeta=\frac{2 D \lambda^{2} X(2 n-1)^{2}}{q[2+\lambda n(n-1)]^{4}}\left(1+\frac{\lambda^{2} n(n-1)(2 n-1)}{6}\right) \\
& +\frac{8 D^{2} \lambda(2 n-1)}{q^{3}[2+\lambda n(n-1)]^{4}}\left(\frac{X \lambda^{2}\left(6 n^{2}-6 n+1\right)}{6}\right. \\
& \left.-\frac{2 D Y}{q^{2}}\right) \\
& +\frac{16 D^{3} \lambda^{2}\left(4 n-4 n^{2}-1\right)\left(A_{1}+A_{2}+n Y\right)}{[2 q+\lambda n(n-1) q]^{5}} \\
& =\frac{2 D \lambda(2 n-1)}{q[2+\lambda n(n-1)]^{4}}[\lambda X(2 n-1) \\
& \cdot\left(1+\frac{\lambda^{2} n(n-1)(2 n-1)}{6}\right) \\
& +\frac{4 D}{q^{2}}\left(\frac{X \lambda^{2}\left(6 n^{2}-6 n+1\right)}{6}-\frac{2 D Y}{q^{2}}\right) \\
& \left.+\frac{8 D^{2} \lambda(2 n-1)\left(A_{1}+A_{2}+n Y\right)}{[2 q+\lambda n(n-1) q]}\right] .
\end{aligned}
$$

From the equation of $\zeta$,

$$
\frac{2 D \lambda(2 n-1)}{q[2+\lambda n(n-1)]^{4}}>0 .
$$

It can be observed that the expression within third bracket is also greater than zero.

Therefore, $\zeta>0$.

As $\left|H_{22}\right|>0$, it implies that $w\left|H_{22}\right|>0$.

Therefore, $\operatorname{det}\left(H_{33}\right)=u^{2} x_{1}+\zeta+w\left|H_{22}\right|>0$.

Now,

$$
\begin{aligned}
\operatorname{det} & \left(H_{44}\right) \\
= & \left|\begin{array}{llll}
\frac{\partial^{2} \mathrm{JTC}(\cdot)}{\partial A_{1}^{* 2}} & \frac{\partial^{2} \mathrm{JTC}(\cdot)}{\partial A_{1}^{*} \partial q^{*}} & \frac{\partial^{2} \mathrm{JTC}(\cdot)}{\partial A_{1}^{*} \partial n^{*}} & \frac{\partial^{2} \mathrm{JTC}(\cdot)}{\partial A_{1}^{*} \partial \lambda^{*}} \\
\frac{\partial^{2} \mathrm{JTC}(\cdot)}{\partial q^{*} \partial A_{1}^{*}} & \frac{\partial^{2} \mathrm{JTC}(\cdot)}{\partial q^{* 2}} & \frac{\partial^{2} \mathrm{JTC}(\cdot)}{\partial q^{*} \partial n^{*}} & \frac{\partial^{2} \mathrm{JTC}(\cdot)}{\partial q^{*} \partial \lambda^{*}} \\
\frac{\partial^{2} \mathrm{JTC}(\cdot)}{\partial n^{*} \partial A_{1}^{*}} & \frac{\partial^{2} \mathrm{JTC}(\cdot)}{\partial n^{*} \partial q^{*}} & \frac{\partial^{2} \mathrm{JTC}(\cdot)}{\partial n^{* 2}} & \frac{\partial^{2} \mathrm{JTC}(\cdot)}{\partial n^{*} \partial \lambda^{*}} \\
\frac{\partial^{2} \mathrm{JTC}(\cdot)}{\partial \lambda^{*} \partial A_{1}^{*}} & \frac{\partial^{2} \mathrm{JTC}_{(\cdot)}}{\partial \lambda^{*} \partial q^{*}} & \frac{\partial^{2} \mathrm{JTC}(\cdot)}{\partial \lambda^{*} \partial n^{*}} & \frac{\partial^{2} \mathrm{JTC}(\cdot)}{\partial \lambda^{* 2}}
\end{array}\right| .
\end{aligned}
$$

Similar to the above, it can be proven that $\operatorname{det}\left(H_{44}\right)>0$.

Finally, it is seen that all principal minors are positive. Hence, the Hessian matrix $H_{i i}$ is positive definite at $\left(n^{*}, q^{*}, \lambda^{*}, A_{1}^{*}\right)$. Therefore, the joint total cost contains the global minimum solution at the optimum solution $\left(n^{*}, q^{*}, \lambda^{*}, A_{1}^{*}\right)$.

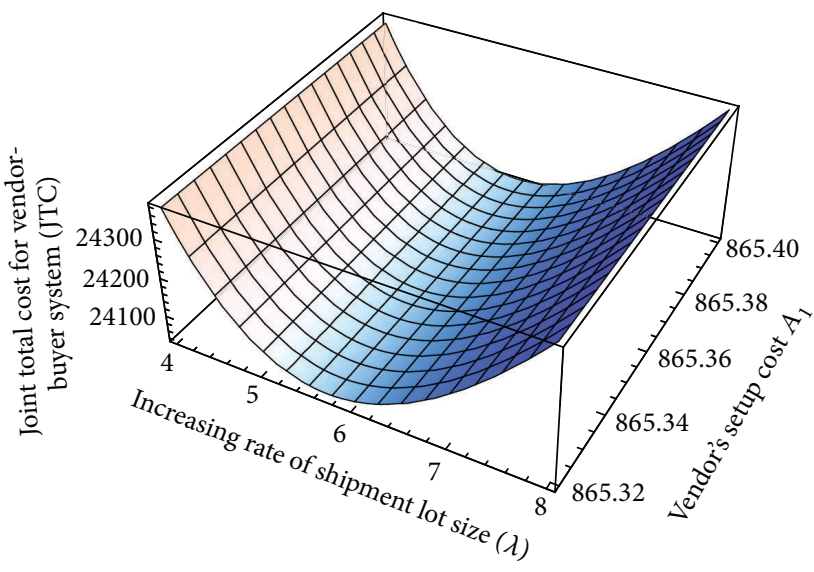

FIGURE 2: Joint total cost for vendor-buyer system (JTC) versus increasing rate of shipment lot size $(\lambda)$ and vendor's setup cost $A_{1}$. When $n$ and $q$ are fixed, $\lambda$ and $A_{1}$ are variable.

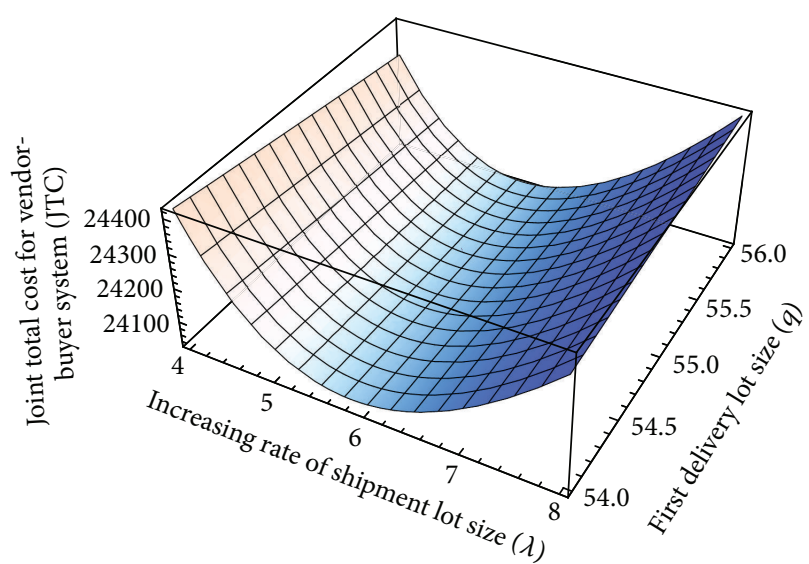

FIGURE 3: Joint total cost for vendor-buyer system (JTC) versus increasing rate of shipment lot size $(\lambda)$ and first delivery lot size $(q)$. When $n$ and $A_{1}$ are fixed, $\lambda$ and $q$ are variable.

\section{Numerical Example}

The parametric values for this model are chosen as

$D=1000$ units/year, $P=4000$ units/year, $A_{2}=$ $\$ 300 /$ order, $A_{3}=\$ 100 /$ shipment, $S_{v}=\$ 5 /$ delivery, $S_{b}$ $=\$ 5 /$ shipment, $S=\$ 0.55 /$ unit, $Y_{b}=\$ 5 /$ unit, $Y_{r}=$ \$15/unit, $\gamma=0.55, Y_{v}=\$ 5 /$ unit, $H_{1}=\$ 35 /$ unit/year, $H_{2}=\$ 30 /$ unit/year, $H_{v}=\$ 20 /$ unit/year, $x=3500$ units/year, $\alpha=0.14, R=16000$, and $A_{0}=$ $\$ 1000 /$ setup.

Then, the joint total cost for vendor-buyer system JTC $=\$ 24045.8$, first delivery lot size of each batch during production $q^{*}=55$ units, vendor's setup cost $A_{1}^{*}=$ $\$ 865.39$, increasing rate of shipment lot size $\lambda^{*}=6$ unit/year, and the number of shipments per batch production $n^{*}=2$ (Figures 2, 3, 4, 5, 6, and 7).

\section{Sensitivity Analysis}

The sensitivity analysis is given for the key parameters of the model in Table 2 . 


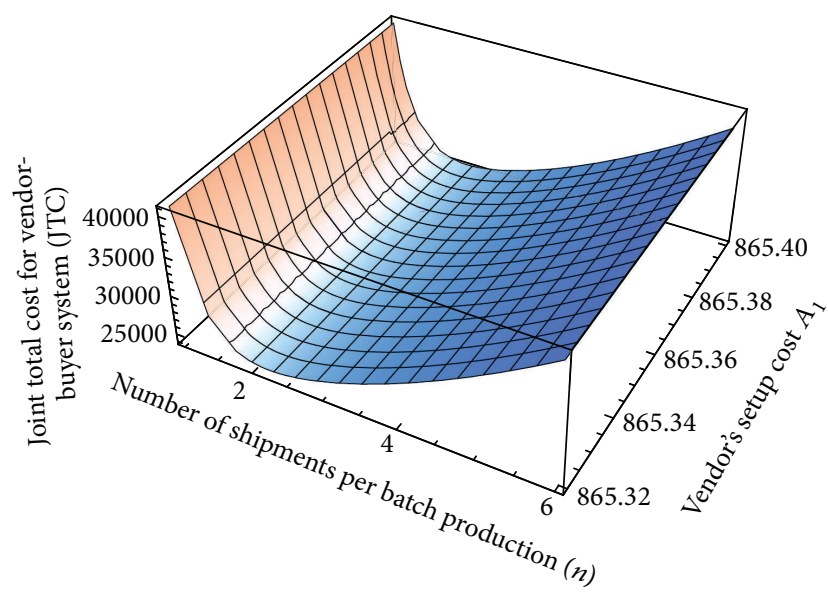

FIGURE 4: Joint total cost for vendor-buyer system (JTC) versus the number of shipments per batch production $(n)$ and vendor's setup cost $A_{1}$. When $q$ and $\lambda$ are fixed, $n$ and $A_{1}$ are variable.

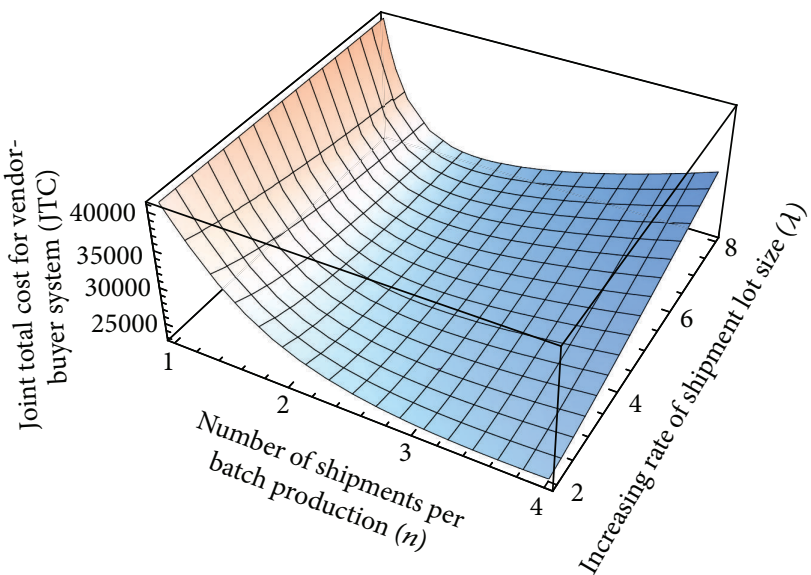

Figure 5: Joint total cost for vendor-buyer system (JTC) versus the number of shipments per batch production $(n)$ and increasing rate of shipment lot size $(\lambda)$. When $q$ and $A_{1}$ are fixed, $n$ and $\lambda$ are variable.

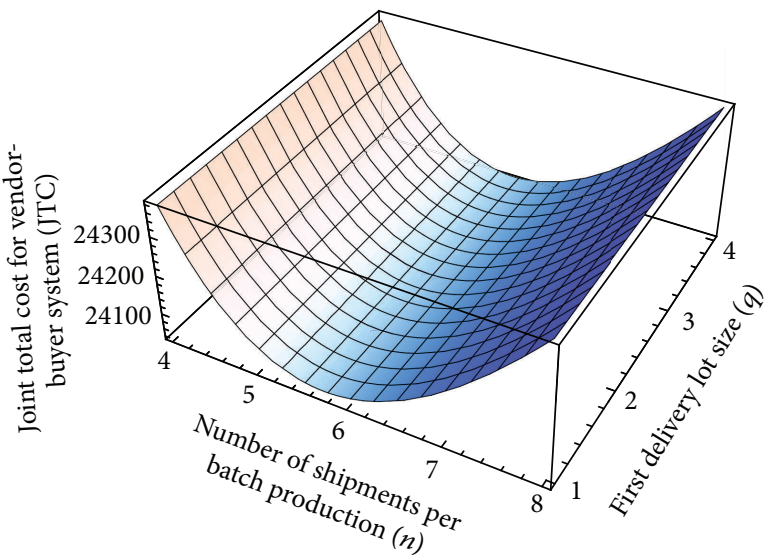

FIGURE 6: Joint total cost for vendor-buyer system (JTC) versus the number of shipments per batch production $(n)$ and first delivery lot size (q). When $\lambda$ and $A_{1}$ are fixed, $n$ and $q$ are variable.

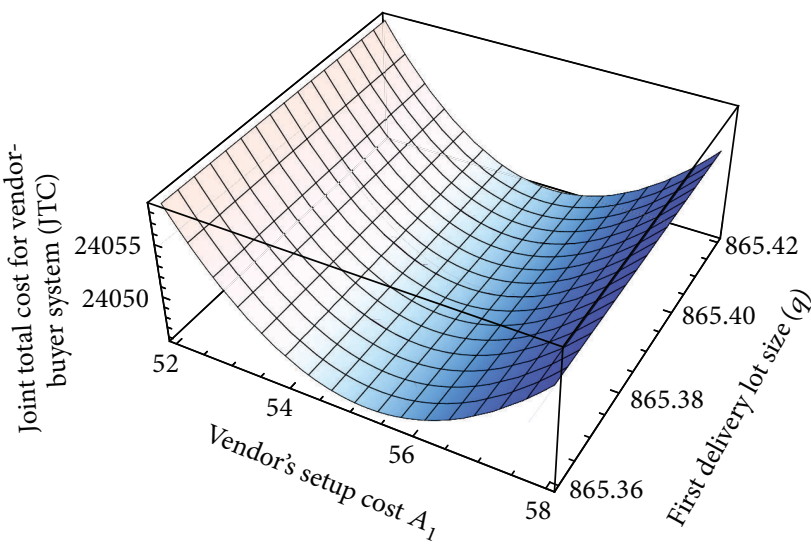

FIGURE 7: Joint total cost for vendor-buyer system (JTC) versus vendor's setup cost $A_{1}$ and first delivery lot size $(q)$. When $n$ and $\lambda$ are fixed, $A_{1}$ and $q$ are variable.

In this section, sensitivity analysis is performed to obtain the effect of several parameters such as $A_{2}, P, S, Y_{r}, S_{v}, S_{b}, Y_{b}$, $Y_{v}, H_{v}$, and $H_{1}$, respectively, on the joint total cost for vendorbuyer system JTC.

(i) The joint total cost for vendor-buyer system JTC increases if ordering cost $A_{2}$, production rate $P$, and inspection cost $S$ increase. For the parameter $A_{2}$, negative percentage change and positive percentage changes are almost similar. In case $P$, negative percentage change is greater than the positive percentage change. This model is equally sensitive in negative as well as equal positive change for parameter $S$.

(ii) If rework cost $Y_{r}$ increases, the joint total cost for vendor-buyer system JTC also increases. The negative percentage change and positive percentage changes in the parameter $Y_{r}$ are similar.

(iii) For the increasing value of the parameter $H_{v}$ which is vendor's holding cost, the joint total cost for vendorbuyer system JTC inclined. The positive percentage change is smaller than the negative percentage change.

(iv) The percentage change in buyer's fixed carbon emission cost $S_{b}$ and vendor's fixed carbon emission cost $S_{v}$ are equal for both positive and negative change. The joint total cost for vendor-buyer system JTC is highly increased if both the parameters $S_{b}$ and $S_{v}$ are increased.

(v) It is seen that if the buyer's variable carbon emission $\operatorname{cost} Y_{b}$ and vendor's variable carbon emission cost $Y_{v}$ increase, then the joint total cost for vendor-buyer system JTC also increases. Both the parameters $Y_{v}$ and $Y_{b}$ are equally sensitive in positive and negative percentage change.

(vi) From Table 2, it can be observed that if the buyer's holding cost for nondefective items, that is, $H_{1}$, rises that means that the joint total cost for vendor-buyer system JTC increases. For $-50 \%$, this model gives infeasible solution. 
TABLE 2: Sensitivity analysis for key parameters.

\begin{tabular}{|c|c|c|}
\hline Parameters & Changes (in \%) & JTC \\
\hline \multirow{4}{*}{$A_{2}$} & $-50 \%$ & -1.68 \\
\hline & $-25 \%$ & -0.82 \\
\hline & $+25 \%$ & 0.8 \\
\hline & $+50 \%$ & 1.59 \\
\hline \multirow{4}{*}{$P$} & $-50 \%$ & -0.17 \\
\hline & $-25 \%$ & -0.04 \\
\hline & $+25 \%$ & 0.02 \\
\hline & $+50 \%$ & 0.03 \\
\hline \multirow{4}{*}{$S$} & $-50 \%$ & -3.14 \\
\hline & $-25 \%$ & -1.57 \\
\hline & $+25 \%$ & 1.57 \\
\hline & $+50 \%$ & 3.14 \\
\hline \multirow{4}{*}{$Y_{r}$} & $-50 \%$ & -15.70 \\
\hline & $-25 \%$ & -7.85 \\
\hline & $+25 \%$ & 7.85 \\
\hline & $+50 \%$ & 15.70 \\
\hline \multirow{4}{*}{$H_{v}$} & $-50 \%$ & -0.28 \\
\hline & $-25 \%$ & -0.14 \\
\hline & $+25 \%$ & 0.13 \\
\hline & $+50 \%$ & 0.25 \\
\hline \multirow{4}{*}{$S_{b}$} & $-50 \%$ & -0.03 \\
\hline & $-25 \%$ & -0.02 \\
\hline & $+25 \%$ & 0.02 \\
\hline & $+50 \%$ & 0.03 \\
\hline \multirow{4}{*}{$S_{v}$} & $-50 \%$ & -0.03 \\
\hline & $-25 \%$ & -0.02 \\
\hline & $+25 \%$ & 0.02 \\
\hline & $+50 \%$ & 0.03 \\
\hline \multirow{4}{*}{$Y_{v}$} & $-50 \%$ & -0.16 \\
\hline & $-25 \%$ & -0.08 \\
\hline & $+25 \%$ & 0.08 \\
\hline & $+50 \%$ & 0.16 \\
\hline \multirow{4}{*}{$Y_{b}$} & $-50 \%$ & -1.57 \\
\hline & $-25 \%$ & -0.78 \\
\hline & $+25 \%$ & 0.78 \\
\hline & $+50 \%$ & 1.57 \\
\hline \multirow{4}{*}{$H_{1}$} & $-50 \%$ & - \\
\hline & $-25 \%$ & -6.76 \\
\hline & $+25 \%$ & 5.62 \\
\hline & $+50 \%$ & 10.46 \\
\hline
\end{tabular}

“-" refers to infeasible solution.

\section{Conclusions}

The paper developed an integrated vendor-buyer model with the setup cost reduction for vendor and effect of carbon emission during transporting items from vendor to buyer. The model considered a logarithmic investment function to reduce the setup cost of vendor. Instead of lot-for-lot (LFL) policy, SSMD policy was used to reduce the holding cost of buyer. In case of LFL policy, holding cost of the buyer was more than the SSMD policy. Increasing holding cost indicated higher joint total cost. Thus, for less joint total cost, SSMD was very useful to reduce the holding cost for buyer. Based on this situation, industry sector will be more beneficial if it use SSMD policy rather than LFL policy. Another major contribution in this model was the unequal delivery lot sizes, while, in the literature, generally SSMD policy was considered with equal lot sizes. Inspection policy is incorporated to this model such that there is a probability to obtain less imperfect items. Beside that, the proposed model reduced the setup cost of vendor by using an investment function. This model minimized the joint total cost for vendor-buyer system considering the setup cost reduction and carbon emission cost. A lemma was constructed to show the global optimum solution of the model. This model extended several models which considered SSMD policy without carbon emission cost or SSMD policy with equal lot sizes, or SSMD policy without setup cost reduction of vendor. This paper can be extended by adding other realistic features such as inspection errors, shortages, and inflation.

\section{Appendix}

The expressions are given for $X, Y$, and $E$ as follows:

$$
\begin{aligned}
& X=\frac{2 D \gamma}{x} H_{2}+(1-\gamma)^{2} H_{1}, \\
& Y=A_{3}+S_{b}+S_{v}, \\
& E=\frac{(P-D)}{4 P}-\frac{(1-\gamma)^{2}}{4}-\frac{\gamma D}{2 x} .
\end{aligned}
$$

\section{Disclosure}

Dr. Biswajit Sarkar is in leave on lien from Vidyasagar University.

\section{Conflict of Interests}

The authors declare that there is no conflict of interests regarding the publication of this paper.

\section{Acknowledgment}

This work was supported by the research fund of Hanyang University (HY-2013-P).

\section{References}

[1] B. Nag and J. K. Parikh, "Carbon emission coefficient of power consumption in India: baseline determination from the demand side," Energy Policy, vol. 33, no. 6, pp. 777-786, 2005.

[2] T. M. Butler, M. G. Lawrence, B. R. Gurjar, J. Van Aardenne, M. Schultz, and J. Lelieveld, "The representation of emissions from megacities in global emission inventories," Atmospheric Environment, vol. 42, no. 4, pp. 703-719, 2008.

[3] C. Ma, M.-T. Ju, X.-C. Zhang, and H.-Y. Li, "Energy consumption and carbon emissions in a coastal city in China," Procedia Environmental Sciences, vol. 4, pp. 1-9, 2011. 
[4] E. Wygonik and A. Goodchild, "Evaluating $\mathrm{CO}_{2}$ emissions, cost, and service quality trade-offs in an urban delivery system case study," IATSS Research, vol. 35, no. 1, pp. 7-15, 2011.

[5] G. Hua, T. C. E. Cheng, and S. Wang, "Managing carbon footprints in inventory management," International Journal of Production Economics, vol. 132, no. 2, pp. 178-185, 2011.

[6] T. M. Bachmann and J. Van Der Kamp, "Environmental costbenefit analysis and the EU (European Union) Industrial Emissions Directive: exploring the societal efficiency of a DeNOx retrofit at a coal-fired power plant," Energy, vol. 68, pp. 125-139, 2014.

[7] G. Zhang, P. Liu, X. Gao, and M. Liu, “Companies' behavior of carbon emission reduction at the risk of oil price volatility," Procedia Computer Science, vol. 31, pp. 291-298, 2014.

[8] J.-D. Hong, S.-L. Kim, and J. C. Hayya, "Dynamic setup reduction in production lot sizing with nonconstant deterministic demand," European Journal of Operational Research, vol. 90, no. 1, pp. 182-196, 1996.

[9] L.-Y. Ouyang, C.-K. Chen, and H.-C. Chang, "Quality improvement, setup cost and lead-time reductions in lot size reorder point models with an imperfect production process," Computers and Operations Research, vol. 29, no. 12, pp. 1701-1717, 2002.

[10] B.-R. Chuang, L.-Y. Ouyang, and K.-W. Chuang, "A note on periodic review inventory model with controllable setup cost and lead time," Computers \& Operations Research, vol. 31, no. 4, pp. 549-561, 2004.

[11] K.-L. Hou, "An EPQ model with setup cost and process quality as functions of capital expenditure," Applied Mathematical Modelling, vol. 31, no. 1, pp. 10-17, 2007.

[12] B. Sarkar and A. Majumder, "Integrated vendor-buyer supply chain model with vendor's setup cost reduction," Applied Mathematics and Computation, vol. 224, pp. 362-371, 2013.

[13] M. Diaby, J. M. Cruz, and A. L. Nsakanda, "Shortening cycle times in multi-product, capacitated production environments through quality level improvements and setup reduction," European Journal of Operational Research, vol. 228, no. 3, pp. 526-535, 2013.

[14] B. Sarkar and I. Moon, "Improved quality, setup cost reduction, and variable backorder costs in an imperfect production process," International Journal of Production Economics, vol. 155, pp. 204-213, 2014.

[15] B. Sarkar, K. S. Chaudhuri, and I. Moon, "Manufacturing setup cost reduction and quality improvement for the distribution free continuous-review inventory model with a service level constraint," Journal of Manufacturing Systems, vol. 34, pp. 7482, 2015.

[16] S. K. Goyal and A. Z. Szendrovits, "A constant lot size model with equal and unequal sized batch shipments between production stages," Engineering Costs and Production Economics, vol. 10, no. 1, pp. 203-210, 1986.

[17] M. A. Hoque and B. G. Kingsman, "An optimal solution algorithm for the constant lot-size model with equal and unequal sized batch shipments for the single product multistage production system," International Journal of Production Economics, vol. 42, no. 2, pp. 161-174, 1995.

[18] R. W. Bogaschewsky, U. D. Buscher, and G. Lindner, "Optimizing multi-stage production with constant lot size and varying number of unequal sized batches," Omega, vol. 29, no. 2, pp. 183191, 2001.

[19] H. Siajadi, R. N. Ibrahim, and P. B. Lochert, "Joint economic lot size in distribution system with multiple shipment policy,"
International Journal of Production Economics, vol. 102, no. 2, pp. 302-316, 2006.

[20] Y.-W. Zhou and S.-D. Wang, "Optimal production and shipment models for a single-vendor-single-buyer integrated system," European Journal of Operational Research, vol. 180, no. 1, pp. 309-328, 2007.

[21] M. A. Hoque, "A manufacturer-buyer integrated inventory model with stochastic lead times for delivering equal- and/or unequal-sized batches of a lot," Computers \& Operations Research, vol. 40, no. 11, pp. 2740-2751, 2013.

[22] M. Hariga, M. Gumus, and A. Daghfous, "Storage constrained vendor managed inventory models with unequal shipment frequencies," Omega, vol. 48, pp. 94-106, 2014.

[23] C.-H. Wang and S.-H. Sheu, "Simultaneous determination of the optimal production-inventory and product inspection policies for a deteriorating production system," Computers \& Operations Research, vol. 28, no. 11, pp. 1093-1110, 2001.

[24] C.-H. Wang and S. H. Sheu, "Determining the optimal production-maintenance policy with inspection errors: using a Markov chain," Computers and Operations Research, vol. 30, no. 1, pp. 1-17, 2003.

[25] C.-H. Wang, "Integrated production and product inspection policy for a deteriorating production system," International Journal of Production Economics, vol. 95, no. 1, pp. 123-134, 2005.

[26] M. Ben-Daya and S. M. Noman, "Integrated inventory and inspection policies for stochastic demand," European Journal of Operational Research, vol. 185, no. 1, pp. 159-169, 2008.

[27] I. Konstantaras, K. Skouri, and M. Y. Jaber, "Lot sizing for a recoverable product with inspection and sorting," Computers and Industrial Engineering, vol. 58, no. 3, pp. 452-462, 2010.

[28] S. H. Yoo, D. Kim, and M.-S. Park, "Lot sizing and quality investment with quality cost analyses for imperfect production and inspection processes with commercial return," International Journal of Production Economics, vol. 140, no. 2, pp. 922-933, 2012.

[29] B. Sarkar and S. Saren, "Product inspection policy for an imperfect production system with inspection errors and warranty cost," European Journal of Operational Research, vol. 248, no. 1, pp. 263-271, 2016.

[30] M. Asghari, "An integrated mathematical model for supplier selection," Industrial Engineering \& Management Systems, vol. 13, no. 1, pp. 29-42, 2014.

[31] Y. Lin, M.-L. Tseng, A. S. F. Chiu, and R. Wang, "Implementation and performance evaluation of a firm's green supply chain management under uncertainty," Industrial Engineering and Management Systems, vol. 13, no. 1, pp. 15-28, 2014.

[32] T. Watanabe and E. Kusukawa, "Optimal operation for green supply chain considering demand information, collection incentive and quality of recycling parts," Industrial Engineering \& Management Systems, vol. 13, no. 2, pp. 129-147, 2014.

[33] R. H. Chen, "Effects of green operations and green innovation on firm's environmental performance," Industrial Engineering and Management Systems, vol. 13, no. 2, pp. 118-128, 2014.

[34] E. Kusukawa, "Supply chain coordination in 2-stage-orderingproduction system with update of demand information," Industrial Engineering and Management Systems, vol. 13, no. 3, pp. 304-318, 2014.

[35] N. Watanabe and E. Kusukawa, "Optimal ordering policy in dual-sourcing supply chain considering supply disruptions and demand information," Industrial Engineering \& Management Systems, vol. 14, no. 2, pp. 129-158, 2015. 


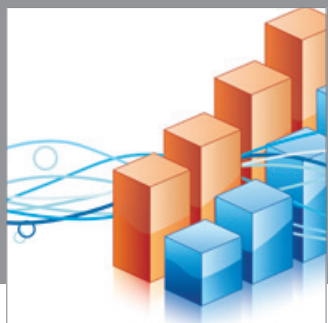

Advances in

Operations Research

mansans

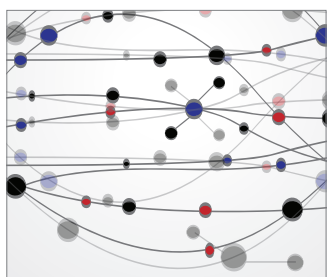

The Scientific World Journal
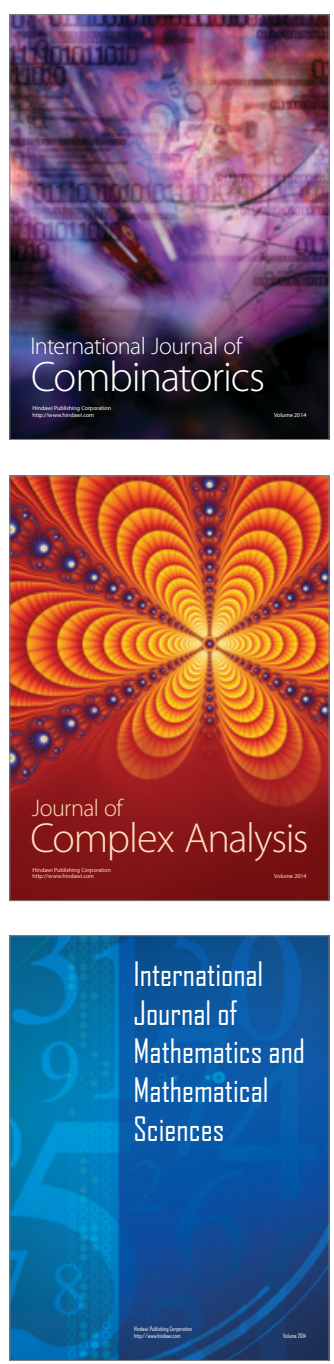
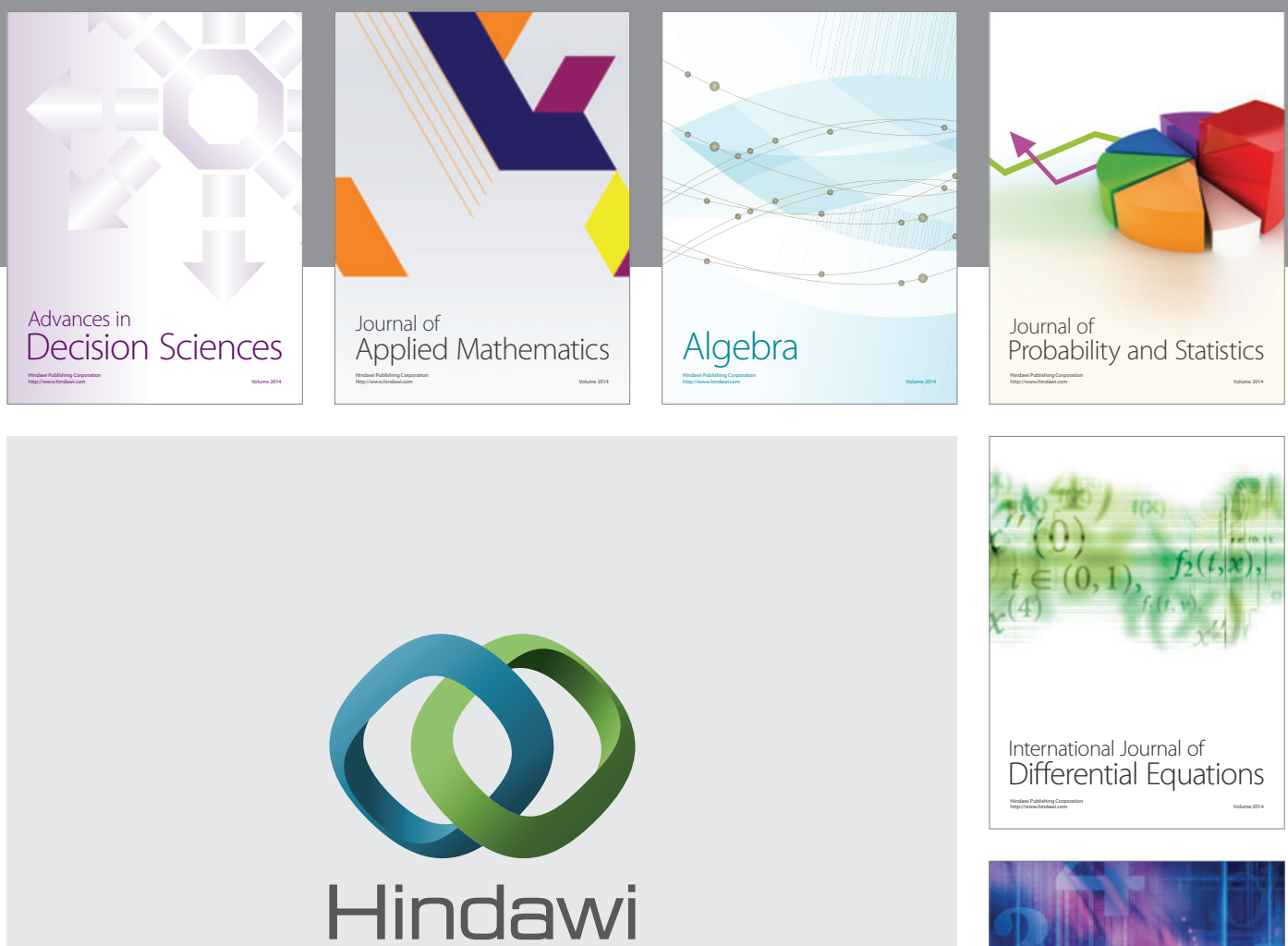

Submit your manuscripts at http://www.hindawi.com
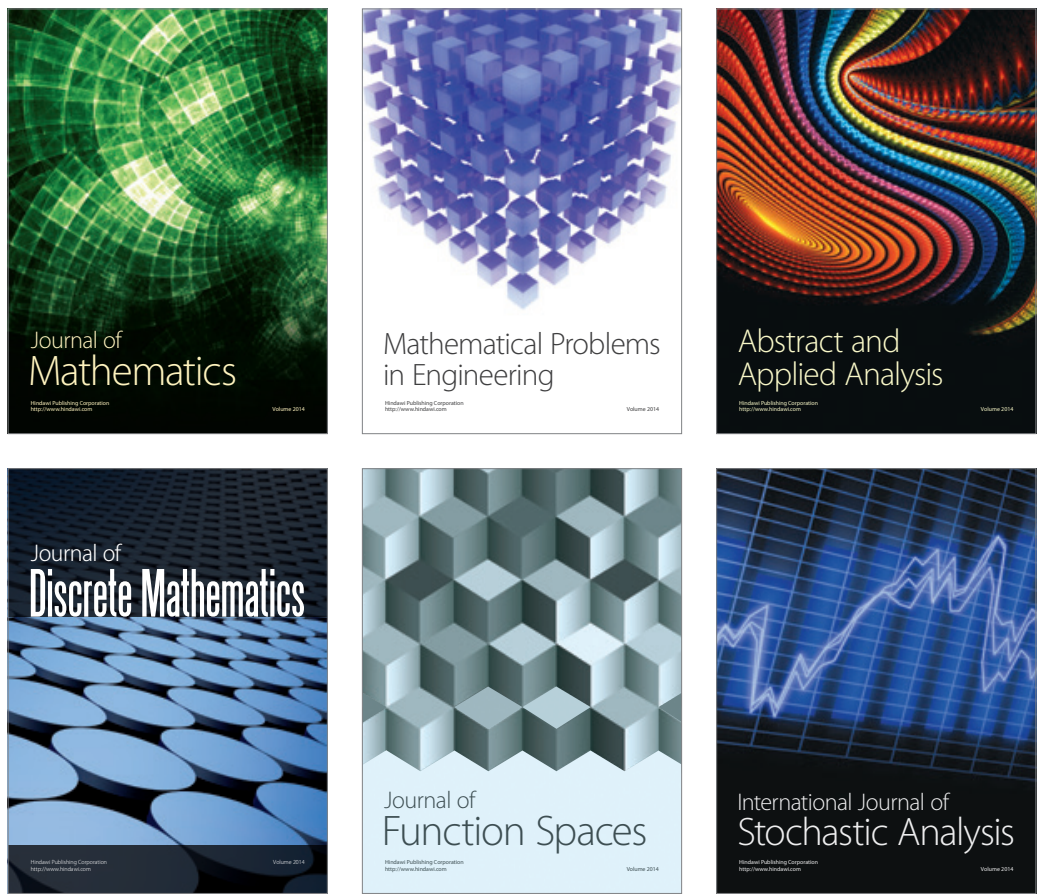

Journal of

Function Spaces

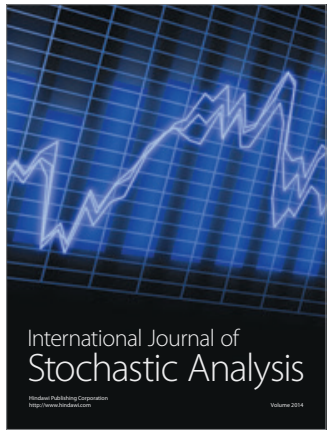

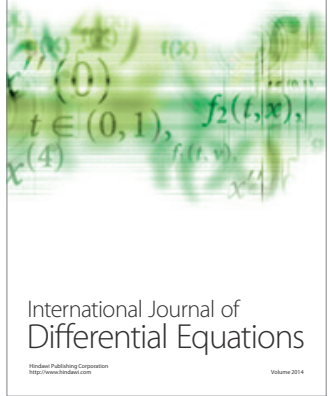
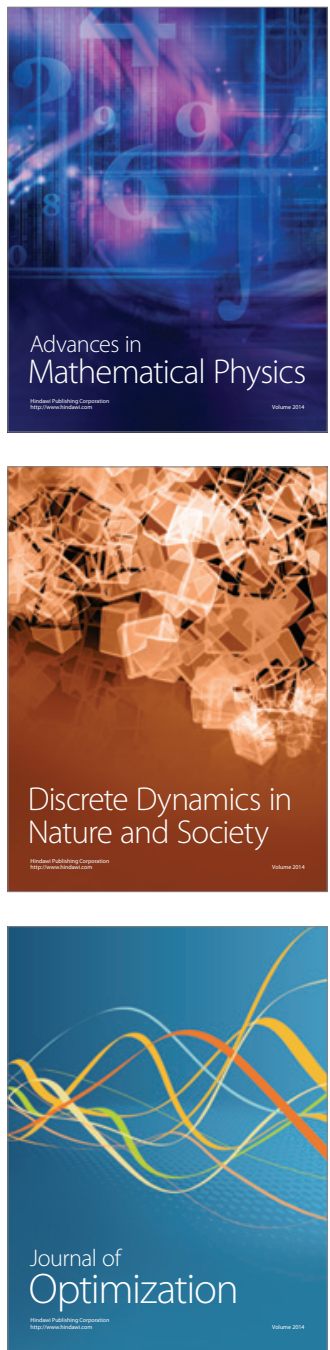